\title{
Study protocol for a randomized controlled trial: Qiliqiangxin in heart failUre: assESsment of reduction in morTality (QUEST)
}

Wenming Yao ${ }^{1+}$, lokfai Cheang ${ }^{1+}$, Shengen Liao ${ }^{1}$, Yanli Zhou ${ }^{1}$, Fang Zhou ${ }^{1}$, Dongjie Xu' ${ }^{1}$, Zhenhua Jia ${ }^{2,3}$, Liping Chang ${ }^{2,3}$, Haifeng Zhang ${ }^{1}$ and Xinli Li ${ }^{1 *}$

\begin{abstract}
Background: Qiliqiangxin (QLQX) capsule is a Traditional Chinese Medicine (TCM) that has been approved in China for the treatment of chronic heart failure (CHF). Our previous study showed with a background of standard HF treatment, QLQX capsules further reduced the levels of NT-proBNP and the incidence of composite cardiac events (CCEs) in CHF patients. This study aims to further assess the reduction in mortality when using QLQX compared with placebo for heart failure with reduced ejection fraction (HFrEF) patients.

Methods: This study is a randomized, double-blind, placebo-controlled, parallel-group, multi-center, event-driven clinical study of approximately 3080 patients for a targeted 620 events. Patients must have a diagnosis of heart failure for at least 3 months prior to screening. Patients will be randomized 1:1 to receive the placebo or QLQX in addition to their standard medications of CHF. The primary efficacy outcome event is a composite cardiovascular death and re-hospitalization due to the worsening of heart failure.

Discussion: The QUEST study is a randomized control study of TCM in chronic heart failure. It will determine the place of QLQX as an new treatment approach and provide additional and innovative information regarding TCM - and the specific used of QLQX in HFrEF.
\end{abstract}

Trial registration: The trial was registered at http://www.chictr.org.cn. ( Registration No.: ChiCTR1900021929); Date: 2019-03-16.

Keywords: Qiliqiangxin (QLQX), Traditional Chinese medicine (TCM), Heart failure, Mortality, Rationale

\section{Background}

In the past decade, Cardiovascular disease is one of the major causes of death globally, seriously threatening human life and health $[1,2]$. The current annual incidence of heart failure (HF) in the United States and Europe is over one million. And there were an estimated 26 millions patients worldwide suffering from HF [3, 4]. A large-scale registry study in China showed there were over 4.5 million patients with HF (prevalence in Chinese adults aged

\footnotetext{
* Correspondence: xinli3267@yeah.net

${ }^{+}$Wenming Yao and lokfai Cheang contributed equally to this work.

'Department of Cardiology, the First Affiliated Hospital with Nanjing Medical

University, Guangzhou Road 300, Nanjing 210029, China

Full list of author information is available at the end of the article
}

35-74 was $0.9 \%$ ). The mortality rate due to cardiovascular diseases accounted for $>40 \%$ of deaths from all-causes in China $[2,5,6]$. The numbers are rapidly increasing due to the aging and expanding population of multiple risk factors for HF, such as aging, hypertension, diabetes mellitus, etc.

In the past 20 years, the concept of drug treatment for heart failure has changed greatly, from the perspective of improving hemodynamics to the point of biological adjustment. Various new treatments and optimized management approaches in heart failure have been suggested. Despite this progress regarding heart failure treatment, the current prevalence and mortality of heart failure remain high. More and more HF patients are turning to complementary and alternative medicine

(c) The Author(s). 2020 Open Access This article is distributed under the terms of the Creative Commons Attribution 4.0 International License (http://creativecommons.org/licenses/by/4.0/), which permits unrestricted use, distribution, and reproduction in any medium, provided you give appropriate credit to the original author(s) and the source, provide a link to the Creative Commons license, and indicate if changes were made. The Creative Commons Public Domain Dedication waiver (http://creativecommons.org/publicdomain/zero/1.0/) applies to the data made available in this article, unless otherwise stated. 
(CAM) to deal with the symptoms and signs of the disease.

The hemodynamic changes caused by early neuroendocrine activation and ventricular remodeling is the basic mechanism in the progressive development of heart failure [7], which is similar from the perspective of traditional Chinese medicine (TCM) [8]. Using the theoretical basis of TCM and modern CAM, Qiliqiangxin (QLQX) was originally designed to treat heart failure.

\section{Qiliqiangxin}

Qiliqiangxin (QLQX) capsule is a specific TCM extract obtained from 11 types of herbs (see "Investigational products" section below). Besides the TCM philosophy, the effect of QLQX capsules might result in preventing phenylephrine-induced cardiac hypertrophy through PPAR $-\gamma$ and its coactivator PGC-1 $\alpha$ [9]. Our previous study showed with background of standard treatment, QLQX further reduced the levels of NT-proB-type Natriuretic Peptide (NT-proBNP), and also demonstrated a superior performance in NYHA heart function, left ventricular ejection fraction (LVEF), 6-min walking distance (6MWD), and for the quality of life [10]. It was approved by the China Food and Drug Administration in 2004 for the treatment of heart failure.

\section{What has still to be done}

QLQX has already showed the effect on attenuating cardiac remodeling in various animal models and the potential to prevent the cardiomyocytes hypertrophy that is characterized in the mechanism of heart failure [11-15]. Our study aims to further explore the efficacy and safety of QLQX capsule compared with placebo in patients with reduced ejection fraction (HFrEF). Herein, we describe the design of "Qiliqiangxin in Heart FailUre: AssESsment of Reduction in MorTality (QUEST)” study.

\section{Methods/design}

\section{Primary and secondary outcomes}

The primary efficacy objective is to demonstrate that QLQX is superior to the placebo in subjects with chronic heart failure (CHF) in addition to conventional heart failure treatment. The primary outcome is the occurrence of the composite endpoint which defined as either cardiovascular (CV) death or re-hospitalization due to the exacerbation of HF.

Secondary outcomes measures include the all-cause mortality, secondary endpoint events (treatment terminated due to worsening heart failure, successful resuscitation after cardiac arrest, malignant arrhythmia, non-fatal stroke), CV death and re-hospitalization due to worsening heart failure in patients with ischemic heart disease, and the level of Serum NT-proBNP.
The assessments of safety and tolerability were based on spontaneous reports of adverse events, vital signs, ECG, and laboratory measurements (complete blood count, routine urinalysis, serum biochemistry, etc.). All endpoint events will be reviewed and determined by the Clinical Event Adjudication Committee (Additional file 1).

\section{Design and patient population}

This study is a randomized, double-blind, placebo-controlled, parallel-group, event-driven, multicenter clinical study.

The study will be event-driven and it is expected that 3080 patients in over 100 centers (mainland China, HongKong, Macau) will be enrolled. All eligible sites are hospital based and are tertiary referral hospitals. Hospitals must have sufficient resources, prior trial experience or a patient population meeting study the selection criteria to allow for adequate recruitment and be able to provide standard heart failure treatment.

All randomized patients will remain in the study (whether taking the study drug or not) until the number of primary endpoint events reaches the predicted value (620 cases), or the study terminates early when it meets the pre-defined efficacy or safety criteria for early termination assessed by the committees (Additional file 1).

The QUEST study will enroll adult ( $\geq 18$ years old) patients, who are clinically stable up to 30 days after a symptomatic event. At the screening visit, patients from both inpatient or outpatient can be assessed according to the inclusion/exclusion criteria (Table 1). Patients need to fulfil all the the inclusion criteria including the LVEF, NT-proBNP, serum sodium, serum potassium, and estimated glomerular filtration rate (eGFR), received treatment, etc., and not meet any exclusion criterion.

The entire study will last for about 36 months, and the recruitment period are expected to be 24 months. Participants will be monitored and assessed by the investigators at each study visit. Termination of the follow-up period will be 12 months after the last eligible enrolled case. Therefore, the shortest follow-up period will be at least 12 months and the average follow-up time will be about 24 months. Patients should visit the hospital for efficacy and safety assessments during the 1st, 3rd, 6th, 9th, and 12th months after the random grouping until the study finishes. Study flowchart is shown in Fig. 1 and the detailed study design is shown in Additional file 2.

Corresponding parameters shown in Fig. 2 including lab and ECG results will be recorded or assessed at each follow-up by the responsible physician on each site. A Data Safety Monitoring Committee (DSMC) will oversee safety in QUEST. The assessment of safety will be based primarily on the frequency of adverse events, SAEs, and laboratory abnormalities. The study plans to perform two interim efficacy analyses 
Table 1 Inclusion and exclusion criteria

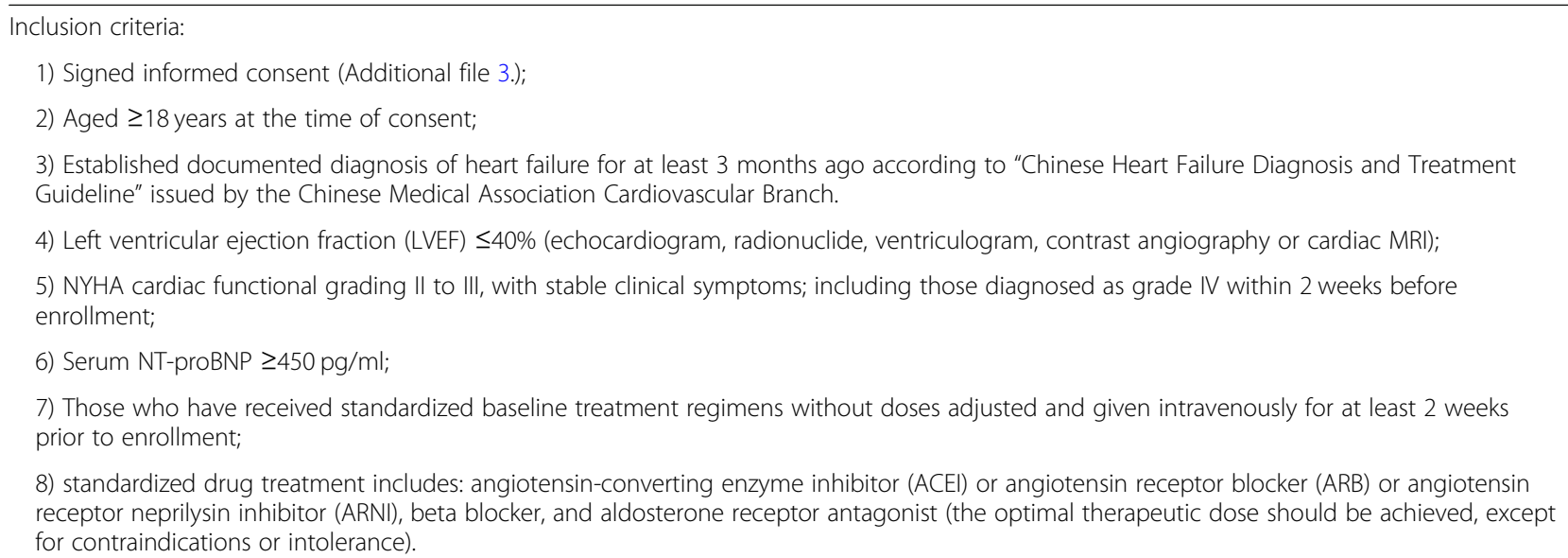

Exclusion criteria:

1) Patients should not enter the study if any of the following exclusion criteria are fulfilled

2) Heart failure caused by valvular disease, congenital heart disease, pericardial disease, arrhythmia or non-cardiaogenic disease, or caused by vital organ failure (such as renal, hepatic failure, etc.); and right heart failure caused by pulmonary or other definite causes; and acute heart failure;

3) Coronary revascularization (percutaneous coronary intervention $[\mathrm{PCI}]$ or coronary artery bypass grafting $[\mathrm{CABG}]$ ) or cardiac synchronization therapy planned to undergo after randomization, or had received cardiac resynchronization therapy prior to enrolment;

4) Any condition outside the CV diseases such as but not limited to malignant tumor, severe mental illness, hematopoietic diseases, neuroendocrine system disease, liver transaminase and alkaline phosphatase $\geq 3 \times$ upper limit of normal (ULN), abnormal renal function serum creatinine $>2 \mathrm{mg} / \mathrm{dl}(176.82 \mathrm{umol} / \mathrm{L})$, potassium $>5.5 \mathrm{mmol} / \mathrm{L}$;

5) Patient with left ventricular outflow tract obstruction, myocarditis, aortic aneurysm, aortic dissection, or obvious hemodynamic changes caused by unrepaired valve;

6) Cardiogenic shock, uncontrollable malignant arrhythmia, sinus or atrioventricular block at second degree type II or above without pacemaker treatment, progressive unstable angina pectoris or acute myocardial infarction;

7) uncontrolled hypertension systolic blood pressure (SBP) $\geq 180 \mathrm{mmHg}$ and/or diastolic blood pressure (DBP) $\geq 110 \mathrm{mmHg}$; or SBP $<90 \mathrm{mmHg}$ and/or DBP < $60 \mathrm{mmHg}$;

8) Participation in another clinical study with an IP during the last month prior to enrolment;

9) Women of child-bearing potential (i.e., those who are not chemically or surgically sterilized or who are not post-menopausal) who are not willing to use a medically accepted method of contraception that is considered reliable in the judgment of the investigator, from the time of signing the informed consent throughout the study and 4 weeks thereafter, OR women who have a positive pregnancy test at enrolment or randomisation OR women who are breast-feeding;

10) Allergic constitution; known to be allergic to research drug;

11) Inability of the patient, in the opinion of the investigator, to understand and/or comply with study medications, procedures or any conditions may render the patient unable to complete the study.

after collecting $1 / 2$ and $2 / 3$ primary endpoints (i.e., approximately 310 and 414 patients, respectively) to identify early in the course of the study any potential safety or tolerability issues and assess whether a valid conclusion has been reached allowing the committee to terminate the study early. The modification of research program should formulate modification description and be carried out after submitting to the Ethics Committee for approval.

This study used Epidata software to collect research data. Throughout the study, data safety monitoring committee will execute the audit and monitoring of research protocol adherence with the assistance of trained clinical research coordinator and clinical research auditor.

\section{Sample size and statistical methods}

It is expected that 3080 patients in over 100 centers (1540 patients per group, 1:1 division into the study group and the control group) will be enrolled and followed up for at least for 12 months. Sample size was estimated referring to the PARADIGM-HF study [16], cardiovascular death or hospitalization rate for heart failure in the median follow-up of 27 months was $21.8 \%$ in the LCZ696 group and $26.5 \%$ in the Enalapril group. We estimate the incidence of cardiovascular death and hospitalization for heart failure is $25 \%$ in all patients receiving basic treatment +placebo group within 36 months of follow-up and $20 \%$ with those receiving basic treatment + QLQX Capsule group. Sample size is estimated by PASS13 software. 


\section{Double-blind Treatment Period: 3 years}

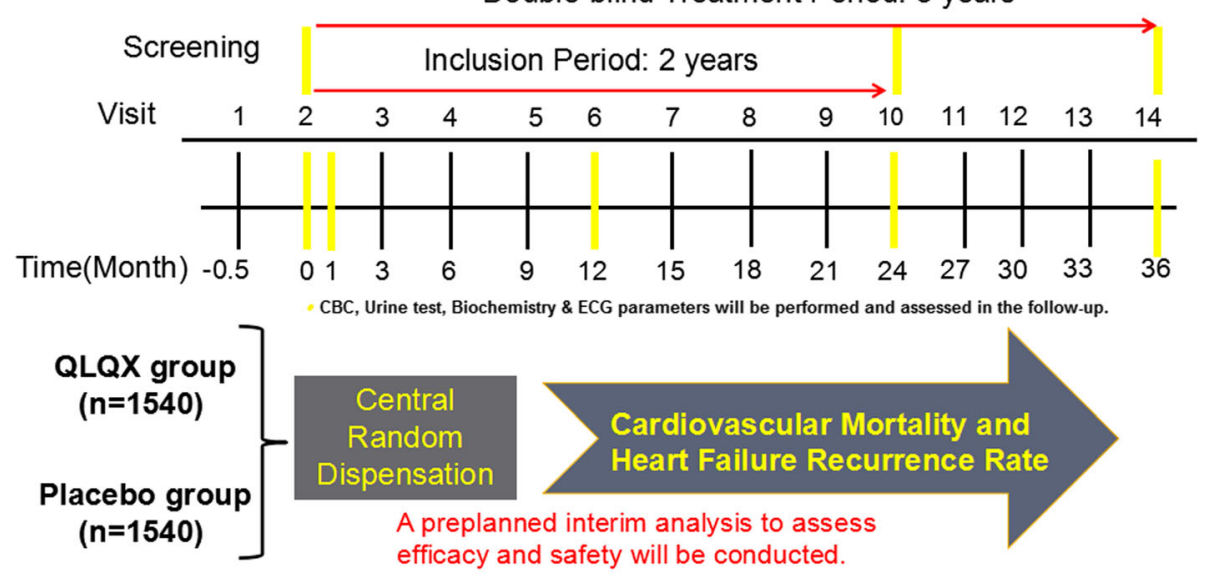

efficacy and safety will be conducted.

Regimen:

The guidelines for diagnosis and treatment of HF in China (2018 Edition) Standardized

medical treatment of heart failure + QL / Placebo 4 capsules Tid

Fig. 1 Study flowchart

The random distribution ratio is $1: 1$ between the study group and the control group. Considering the consumption of type I error in the interim analysis, $\alpha$ is adjusted to unilateral 0.02314 . The sample size is the number of cases with composite endpoints events. It is expected that 620 composite endpoint events need be observed to provide $80 \%$ power of test $(\beta=0.2)$, and the $20 \%$ risk can be reduced in the study group by the log-rank test.

Statistical specialists at Peking University Clinical Research Institute adopts $\mathrm{SAS}^{\circ} 9.4$ software (or higher version) package to generate random numbers using the block randomization method according to the ratio of 1:1 between study group and control group. The study drug (QLQX or placebo capsules) will be packaging according to this random number by a person unrelated to the study.

A randomization and trail supply management system (RTSM) is used in the study, and statistical professionals will provide a random numbered list to the RTSM. The patient is then assigned a random number by the RTSM. Unblinding will be available in case of adverse events.

After completing baseline assessment, random numbers are assigned by RTSM during baseline visits. After that, the drug number is obtained through the RTSM according to the interview plan, and the serial number of drug assigned each time is different, but the drugs are the same. Before randomization of the patient, the researcher must first log into the RTSM and provide the according information (e.g. the subject's date of birth, gender, etc.).

Two interim analyses during and full analysis after the study will be performed by independent statisticians from Peking University Clinical Research Institute who will not be involved in the trial conduct. Demographic characteristics, efficacy analysis, compliance analysis, and safety analysis will be performed in these time points. $P$ value less than or equal to 0.05 (two-sided test) is considered with statistical difference (unless specified otherwise). Our descriptive statistics will include means and SDs, medians and interquartile ranges for continuous variables, and the number and proportions for categorical variables as appropriate. We will compare the two intervention groups regarding their characteristics with paired t-test, Wilcoxon rank sum test, chi-square test, precise probability method, or Cochran-Mantel-Haenszel test based on the type of variables.

\section{Investigational products (IP)}

QLQX and the matching placebo capsules have identical characters as shown in Table 2. IPs will be packed in identical package and label. Eligible patients were randomly assigned to 2 groups that received either QLQX or a placebo (in a 1:1 ratio; double blinded; provided as identical in size and shape) in addition to their standard HF treatment following the guidelines for diagnosis and treatment of HF in China 2018 [17] or local guideline. Participants should not have used any TCM or herbs having similar contents to the IP, such as Danshen and Tongxinluo Capsules. The dosage used in this study was 4 capsules of QLQX or placebo 3 times daily. Patients were recommended to administrate the IPs $30 \mathrm{~min}$ after meal, and should also be separated by a minimum 30 min interval with other medications.

At any time after randomization, patients are free to discontinue for any reason. The reason for the withdrawal should be acquired and recorded in the case report form. If the patient has an intolerable adverse event, which is relevant to the study drug according to the judgment of researcher, the patient should terminate treatment with the study drug. 


\begin{tabular}{|c|c|c|c|c|c|c|c|c|c|c|c|c|c|c|c|c|}
\hline Visit & 1. & 2. & 3. & 4. & 5. & 6. & 7. & 8. & \begin{tabular}{|l|}
9. \\
.
\end{tabular} & 10. & 11. & 12. & 13. & $\mid 14$. & UNS & EOS \\
\hline \multirow[t]{2}{*}{ Day/month } & Day0 & $1 \mathrm{M}$ & $3 \mathrm{M}$ & $6 \mathrm{M}$ & 9M & $12 \mathrm{M}$ & $15 \mathrm{M}$ & $18 \mathrm{M}$ & $21 \mathrm{M}$ & $24 \mathrm{M}$ & $27 \mathrm{M}$ & $30 \mathrm{M}$ & $33 \mathrm{M}$ & $36 \mathrm{M}$ & & \\
\hline & -14 & \pm 3 & \pm 7 & \pm 7 & \pm 7 & \pm 7 & \pm 7 & \pm 7 & \pm 7 & \pm 7 & \pm 7 & \pm 7 & \pm 7 & \pm 7 & & $\begin{array}{c}=2 \\
\text { weeks }\end{array}$ \\
\hline Informed consent & $x$ & & & & & & & & & & & & & & & \\
\hline Inclusion/exclusion criteria & $x$ & & & & & & & & & & & & & & & \\
\hline Randomization & $x$ & & & & & & & & & & & & & & & \\
\hline General data and medical history & $x$ & & & & & & & & & & & & & & & \\
\hline Medical history of HF & $x$ & & & & & & & & & & & & & & & \\
\hline Medical history of CV Disease & $x$ & & & & & & & & & & & & & & & \\
\hline Physical Examination & $x$ & $x^{1}$ & $x^{1}$ & $x^{1}$ & $\mathrm{x}^{1}$ & $x$ & $x^{1}$ & $x^{1}$ & $x^{1}$ & $x$ & $x^{1}$ & $x^{1}$ & $x^{1}$ & $x$ & $(\mathrm{x})$ & $x$ \\
\hline Heart failure medications & $x$ & $x$ & $x$ & $x$ & $x$ & $x$ & $x$ & $x$ & $x$ & $x$ & $x$ & $x$ & $x$ & $x$ & $(x)$ & $x$ \\
\hline Medications of other CVD & $x$ & $x$ & $x$ & $x$ & $x$ & $x$ & $x$ & $x$ & $x$ & $x$ & $x$ & $x$ & $x$ & $x$ & $(x)$ & $x$ \\
\hline Other medications & $\mathrm{x}$ & $x$ & $x$ & $x$ & $x$ & $x$ & $x$ & $x$ & $x$ & $x$ & $\mathrm{x}$ & $x$ & $x$ & $x$ & $(x)$ & $\mathrm{x}$ \\
\hline Echocardiogram & $x^{*}$ & & & & & & & & & & & & & & & \\
\hline Pregnancy tests & $x$ & & & & & $x$ & & & & $x$ & & & & $x$ & $(x)$ & $x$ \\
\hline Blood/urine routine test & $x$ & $x$ & & & & $x$ & & & & $x$ & & & & $x$ & $(x)$ & $x$ \\
\hline Biochemical test & $x$ & $x$ & & & & $x$ & & & & $x$ & & & & $x$ & $(x)$ & $x$ \\
\hline 12-lead ECG & $x^{*}$ & $x$ & & & & $x$ & & & & $x$ & & & & $x$ & $(\mathrm{x})$ & $x$ \\
\hline $\begin{array}{c}\text { Serum NT-proBNP at local } \\
\text { laboratory }\end{array}$ & $x$ & & & & & & & & & & & & & & & \\
\hline $\begin{array}{c}\text { SerumNT-proBNP at central } \\
\text { laboratory }\end{array}$ & $x$ & $x$ & & $x$ & & & & & & & & & & & & \\
\hline Dispensing IP & $x$ & & $x$ & $x$ & $x$ & $x$ & $x$ & $x$ & $x$ & $x$ & $x$ & $x$ & $x$ & $x$ & & \\
\hline Returning IP for accountability & & & $x$ & $x$ & $x$ & $x$ & $x$ & $x$ & $x$ & $x$ & $x$ & $x$ & $x$ & $x$ & & $\mathrm{x}$ \\
\hline Endpoint Event & & $x$ & $x$ & $x$ & $x$ & $x$ & $x$ & $x$ & $x$ & $x$ & $x$ & $x$ & $x$ & $x$ & $(x)$ & $x$ \\
\hline Adverse Event & & $x$ & $x$ & $x$ & $x$ & $x$ & $\mathrm{x}$ & $x$ & $x$ & $x$ & $x$ & $x$ & $x$ & $x$ & $(\mathrm{x})$ & $x$ \\
\hline Serious Adverse Event & & $x$ & $x$ & $x$ & $x$ & $x$ & $x$ & $x$ & $x$ & $x$ & $x$ & $x$ & $x$ & $\mathrm{x}$ & $(x)$ & $x$ \\
\hline $\begin{array}{l}\times^{1} \text { Simplified physical exar } \\
\text { - } \quad{ }^{*} \text { Cardiac ultrasound } \\
\text { - UNS (unplanned visit): } \\
\text { - EOS (final visit): Make } \\
\text { end of study, it is regar } \\
\text { - Pregnancy test is only } \\
\text { confirmed by serum pr }\end{array}$ & $\begin{array}{l}(\mathrm{x}) \\
\text { arr }\end{array}$ & emen & $\begin{array}{l}\text { ked it } \\
\text { t acco } \\
1 \text { visit } \\
\text { o wo }\end{array}$ & $\begin{array}{l}\text { em is } \\
\text { ording } \\
\text { but } \\
\text { men }\end{array}$ & $\begin{array}{l}\text { op } \\
\text { to } \\
\text { nee } \\
\text { of c }\end{array}$ & $\begin{array}{l}\text { irst } 6 \\
\text { hal and } \\
\text { te stuc } \\
\text { to be }\end{array}$ & $\begin{array}{l}\mathrm{p} \\
\text { ly } \\
\text { su } \\
\text { ing }\end{array}$ & $\mathrm{me}$ & $\begin{array}{l}\mathrm{d} \text { acc } \\
\mathrm{e} \text { (if th } \\
\text { nted } \\
\text { the ur }\end{array}$ & $\begin{array}{l}\text { ment; } \\
\text { ording } \\
\text { here is } \\
\text { vith th } \\
\text { rine pr }\end{array}$ & $\begin{array}{l}\text { a vis } \\
\text { e item } \\
\text { regnan }\end{array}$ & $\begin{array}{l}\text { e judg } \\
\text { it with } \\
\text { s requ } \\
\text { ccy te }\end{array}$ & $\begin{array}{l}\text { ment } \\
\text { in on } \\
\text { iired } \\
\text { st is } p\end{array}$ & $\begin{array}{l}\text { of res } \\
\text { e mon } \\
\text { compl } \\
\text { ositiv }\end{array}$ & $\begin{array}{l}\text { earch } \\
\text { th bef } \\
\text { etely) } \\
e, \text { it } n\end{array}$ & $\begin{array}{l}\text { rs. } \\
\text { re the } \\
\text { ust be }\end{array}$ \\
\hline
\end{tabular}

Fig. 2 Planned visits and parameters

\section{Discussion}

Recent years, HF treatment strategy based on dual RAAS blockade and natriuretic peptide augmentation have been explored. The prognosis for heart failure has improved based on the optimal use of neurohormonal antagonists such as angiotensin-converting enzyme inhibitors, betablockers, aldosterone antagonists, and neprilysin inhibitors
[18]. Despite advances in management and treatment of chronic heart failure with reduced ejection fraction (HFrEF), HF continues to be a major cause of mortality, initial and recurrent hospitalizations, and sub-optimal quality of life. On the other hand, myocardial remodeling is the basic mechanism of heart failure, including pathological cardiomyocyte hypertrophy with re-expression of

Table 2 Characteristics of the Investigational Product

\section{Study drug: Qiliqiangxin Capsule (莙劳强心胶囊)}

-Ingredients: Astragalus, Ginseng, Monkshood, Danshen, Pepperweed Seed, Rhizoma Alismatis, Radix Polygonati Officinalis, Cassia Twig, Red Flower, Cortex Periplocae, Tangerine Peel

-Property: Capsule; the contents are brown to black brown granules; bitter in taste;

-Specification: $0.3 \mathrm{~g} /$ granule

-Bach number: GYZZ Z20040141

-Manufacturer: Shijiazhuang Yiling Pharmaceutical Co., Ltd.

Placebo: Qiliqiangxin Matching Placebo

-With identical color, specification, packaging, property of contents and other features with Qiliqiangxin Capsule 
embryonic genes, cardiomyocyte apoptosis and necrosis, and excessive deposition or degradation of myocardial extracellular matrix [19]. Researches regarding these mechanism in HF treatment continues to be undertaken.

Qiliqiangxin (QLQX) is a widely used TCM in CHF treatment in China. With the assistance of translational medical science, its efficacy against cardiac hypertrophy and remodeling has been demonstrated in various studies. Results showed the effects of QLQX in multiple mechanism pathways in treating CHF, such as by regulating the balance of proinflammatory and anti-inflammatory cytokines [20], down-regulating the cardiac chymase signaling pathway and chymase-mediated angiotensin II production [21], inhibiting the myocardial inflammation and cardiomyocyte death to promoted cardiomyocyte proliferation [22].

In our previous multi-centers, randomized, doubleblind, parallel-group, placebo-controlled study [10], a total 512 patients were enrolled to explored the effects of QLQX. Results showed on a background of standard treatment, QLQX capsules further reduced the levels of NT-proBNP. Furthermore, fewer deaths and re-admissions for heart failure were observed in the Qiliqiangxin group. Although the mortality differences between groups were not significant, these suggested QLQX in combination therapy for CHF could improve the outcome of patients with CHF. Therefore, to explore the efficacy and safety of QLQX in HFrEF patients, this study include a larger cohort and a longer followup period.

In QUEST study, a longer-term follow up will lead to a better understanding of the comparative benefit regarding the effect of QLQX in CHF and will answer the question of our last relatively short-term randomized controlled study.

The cohort designs is similar PARADIGM-HF. However, QUEST study has the threshold of NT-proBNP $\geq 450 \mathrm{pg} /$ $\mathrm{mL}$. Although the clinical value of BNP and NT-proBNP were well-established and are the most widely used biomarkers in differential diagnosis, risk stratification and prognostic evaluation of heart failure; nowadays with the increasing number of patients in the regimen of angiotensin receptor-neprilysin inhibitor (ARNi), BNP level can be affected significantly [23] and therefore were not included.

Also, as mentioned above, the mortality differences between groups were not significant in our previous relatively short-term study. A larger population and the basis of $\mathrm{CV}$ mortality to detect a clinically meaningful reduction in the primary composite outcome are estimated by the statistic specialist. The primary outcome of $\mathrm{CV}$ death or heart failure hospitalization was chosen to further address questions regarding the hard endpoint events in HFrEF patients.

Our study officially started in May, 2019 and is now ongoing, collecting patients and data. Regarding TCM in treatment of heart failure, the QUEST study is an eventdriven randomized control study designed to provide additional information on TCM and further assess the effectiveness of Qiliqiangxin capsules in HFrEF patients.

\section{Supplementary information}

Supplementary information accompanies this paper at https://doi.org/10. 1186/s12906-020-2821-0.

Additional file 1. List of the QUEST Committees and Investigators.

Additional file 2. 2019-05 QUEST-EN (only for review).

Additional file 3. Informed consent form.

\section{Abbreviations}

6MWD: 6-min Walking Distance; ARNi: Angiotensin Receptor-Neprilysin Inhibitor; CCE: Composite Cardiac Event; CHF: Chronic Heart Failure;

CV: Cardiovascular; DSMC: Data Safety Monitoring Committee;

eGFR: Estimated Glomerular Filtration Rate; HF: Heart Failure; HFrEF: Heart

Failure with Reduced Ejection Fraction; IP: Investigational Products; LVEF: Left Ventricular Ejection Fraction; NT-proBNP: NT-proB-type Natriuretic Peptide; NYHA: New York Heart Association; QLQX: Qiliqiangxin; TCM: Traditional

Chinese Medicine

\section{Acknowledgments}

The authors gratefully acknowledge the contributions of the sites and all participants in the previous study.

\section{Authors' contributions}

WMY participated in design of the research and drafted the manuscript. IFC was a major contributor in writing the manuscript. SGL and HFZ performed the analysis and interpretation of the study statistic design. YLZ, FZ and DJX supervised the study program and method feasibility. ZHJ and LPC contributed obtaining funding and the contact with multi-center. HFZ and $\mathrm{XLL}$ contributed conception and design of the research. XLL also performed critical revision of the manuscript for important intellectual content. All authors read and approved the final manuscript.

\section{Funding}

QUEST is funded by National Key Technologies R\&D Program, Modernization of Traditional Chinese Medicine of Ministry of Science and Technogy of the People's Republic of China (Project No. 2017YFC1700501, 2017YFC1700505) and the Major Program of the National Natural Science Foundation of China (81730106).

Qiliqiangxin capsules and the matching placebos are provided by

Shijiazhuang Yiling Pharmaceutical Co., Ltd. (Shijiazhuang, People's Republic of China).

The above funding sources have no involvement in the design of the study and collection, analysis, interpretation of data and in writing the manuscript.

\section{Availability of data and materials}

Not applicable.

\section{Ethics approval and consent to participate}

All participating centers must obtain approval from appropriate independent ethics committees or institutional review boards (Approved No. of ethic committee: 2018-SR-275). The study will be conducted in accordance with the principles of Good Clinical Practice and the Declaration of Helsinki. The trial was registered at http://www.chictr.org.cn - ChiCTR1900021929. All participants must give written informed consent (Additional file 3) which should be acquired after sufficient and detailed explanation to research situation (including confidentiality, risk and benefits, purpose of the study, etc.). 


\section{Competing interests}

The operation of the program has undergone peer-review by the funding body for budget review. The design of the study, data collection, data analysis and interpretation are independent to the funding body.

All executive committee members have received consulting fees as well as travel and research support in the planning and conduct of the QUEST study. The authors declare that they have no other conflict of interest to disclose.

\section{Author details}

'Department of Cardiology, the First Affiliated Hospital with Nanjing Medical University, Guangzhou Road 300, Nanjing 210029, China. ${ }^{2}$ National Key Laboratory of Collateral Disease Research and Innovative Chinese Medicine, Shijiazhuang, China. ${ }^{3}$ Hebei Yiling Hospital, Key Disciplines of State Administration of TCM for Collateral Disease, Shijiazhuang, China.

Received: 12 June 2019 Accepted: 20 January 2020

Published online: 05 February 2020

\section{References}

1. Joseph P, Leong D, McKee M, et al. Reducing the global burden of cardiovascular disease, part 1: the epidemiology and risk factors. Circ Res. 2017;121(6):677-94. https://doi.org/10.1161/CIRCRESAHA.117.308903.

2. Shen C, Ge J. Cardiovascular branch of Chinese Medical Association. Epidemic of cardiovascular disease in China. Circulation. 2018;138(4):342-4. https://doi.org/10.1161/CIRCULATIONAHA.118.033484.

3. Mozaffarian D, Benjamin EJ, Go AS, et al. American Heart Association statistics C, stroke statistics S. heart disease and stroke statistics--2015 update: a report from the American Heart Association. Circulation. 2015;131: e29-322. PMID: 25520374. https://doi.org/10.1161/CIR.0000000000000152.

4. Ambrosy AP, Fonarow GC, Butler J, Chioncel O, Greene SJ, Vaduganathan M, Nodari S, Lam CSP, Sato N, Shah AN, Gheorghiade M. The global health and economic burden of hospitalizations for heart failure: lessons learned from hospitalized heart failure registries. J Am Coll Cardiol. 2014;63:1123-33. PMID: 24491689. https://doi.org/10.1016/j.jacc.2013.11.053.

5. Chen WW, Gao RL, Liu LS, et al. Outline of the report on cardiovascular disease in China, 2014. Eur Heart J Suppl. 2016;18(Suppl F):F2-F11. PMID: 28533724. https://doi.org/10.1093/eurheartj/suw030.

6. Hu SS, Kong LZ, Gao RL, et al. Outline of the report on cardiovascular disease in China, 2010. Biomed Environ Sci. 2012;25(3):251-6. https://doi. org/10.3967/0895-3988.2012.03.001.

7. Mentz RJ, O'Connor CM. Pathophysiology and clinical evaluation of acute heart failure. Nat Rev Cardiol. 2016;13(1):28-35. https://doi.org/10.1038/ nrcardio.2015.134

8. Yiling WU. Meridian theory [M]: China Science and Technology Press; 2010

9. Gao RR, Wu XD, Jiang HM, et al. Traditional Chinese medicine Qiliqiangxin attenuates phenylephrine-induced cardiac hypertrophy via upregulating PPARy and PGC-1a. Ann Transl Med. 2018;6(8):153. https://doi.org/10.21037/ atm.2018.04.14.

10. Li X, Zhang J, Huang J, et al. A multicenter, randomized, double-blind, parallel-group, placebo-controlled study of the effects of qili qiangxin capsules in patients with chronic heart failure. J Am Coll Cardiol. 2013;62: 1065-72. https://doi.org/10.1016/j.jacc.2013.05.035.

11. Tao L, Shen S, Fu S, Fang H, Wang X, Das S, Sluijter JP, Rosenzweig A, Zhou Y, Kong X, Xiao J, Li X. Traditional Chinese medication Qiliqiangxin attenuates cardiac remodeling after acute myocardial infarction in mice. Sci Rep. 2015;5:8374. https://doi.org/10.1038/srep08374.

12. Zhang H, Li S, Zhou Q, Sun Q, Shen S, Zhou Y, Bei Y, Li X. Qiliqiangxin attenuates phenylephrine-induced cardiac hypertrophy through downregulation of MiR-199a-5p. Cell Physiol Biochem. 2016;38:1743-51. https://doi.org/10.1159/000443113.

13. Zhou Y, Fang H, Lin S, Shen S, Tao L, Xiao J, Li X. Qiliqiangxin protects against cardiac ischemia-reperfusion injury via activation of the mTOR pathway. Cell Physiol Biochem. 2015;37:454-64. https://doi.org/10.1159/000430368.

14. Lin S, Wu X, Tao L, Bei Y, Zhang H, Zhou Y, Shen S, Xiao J, Li X. The metabolic effects of traditional Chinese medication Qiliqiangxin on $\mathrm{H} 9 \mathrm{C} 2$ cardiomyocytes. Cell Physiol Biochem. 2015;37:2246-56. https://doi.org/10. 1159/000438580

15. Zhang J, Huang M, Shen S, Wu X, Wu X, Lv P, Zhang H, Wang H, Li X. Qiliqiangxin attenuates isoproterenol-induced cardiac remodeling in mice. Am J Transl Res. 2017;9(12):5585-93 PMID: 29312510.
16. McMurray JJ, Packer M, Desai AS, et al. Dual angiotensin receptor and neprilysin inhibition as an alternative to angiotensin-converting enzyme inhibition in patients with chronic systolic heart failure: rationale for and design of the prospective comparison of ARNI with ACEI to determine impact on global mortality and morbidity in heart failure trial (PARADIGM-HF). Eur J Heart Fail. 2013;15(9):1062-73. https://doi.org/10.1093/eurjhf/hft052.

17. Heart Failure Group of Chinese Society of Cardiology of Chinese Medical Association; Chinese Heart Failure Association of Chinese Medical Doctor Association; Editorial Board of Chinese Journal of Cardiology. Chinese guidelines for the diagnosis and treatment of heart failure 2018. Zhonghua Xin Xue Guan Bing Za Zhi 2018;46(10):760-789. doi: https://doi.org/10.3760/ cma.j.issn.0253-3758.2018.10.004.

18. Simpson J, Jhund PS, Silva Cardoso J, et al. PARADIGM-HF investigators and committees. Comparing LCZ696 with enalapril according to baseline risk using the MAGGIC and EMPHASIS-HF risk scores: an analysis of mortality and morbidity in PARADIGM-HF. J Am Coll Cardiol. 2015;66(19):2059-71. https://doi.org/10.1016/j.jacc.2015.08.878.

19. Peterzan MA, Lygate CA, Neubauer S, Rider OJ. Metabolic remodeling in hypertrophied and failing myocardium: a review. Am J Physiol Heart Circ Physiol. 2017;313(3):H597-616. https://doi.org/10.1152/ajpheart.00731.2016

20. Xiao H, Song Y, Li Y, Liao YH, Chen J. Qiliqiangxin regulates the balance between tumor necrosis factor-alpha and interleukin-10 and improves cardiac function in rats with myocardial infarction. Cell Immunol. 2009; 260(1):51-5. https://doi.org/10.1016/j.cellimm.2009.09.001.

21. Liu W, Chen J, Xu T, Tian W, et al. Qiliqiangxin improves cardiac function in spontaneously hypertensive rats through the inhibition of cardiac chymase. Am J Hypertens. 2012;25(2):250-60. https://doi.org/10.1038/ajh.2011.219.

22. Zou Y, Lin L, Ye Y, Wei J, et al. Qiliqiangxin inhibits the development of cardiac hypertrophy, remodeling, and dysfunction during 4 weeks of pressure overload in mice. J Cardiovasc Pharmacol. 2012;59(3):268-80. https://doi.org/10.1097/FJC.0b013e31823f888f.

23. Yancy CW, Jessup M, Bozkurt B, Butler J, Casey DE Jr, Colvin MM, Drazner MH, Filippatos GS, Fonarow GC, Givertz MM, Hollenberg SM, Lindenfeld J, Masoudi FA, McBride PE, Peterson PN, Stevenson LW, Westlake C. 2017 ACC/AHA/HFSA focused update of the 2013 ACCF/AHA guideline for the Management of Heart Failure: a report of the American College of Cardiology/American Heart Association task force on clinical practice guidelines and the Heart Failure Society of America. Circulation. 2017;136(6):e137-61. https://doi.org/10.1161/ CIR.0000000000000509.

\section{Publisher's Note}

Springer Nature remains neutral with regard to jurisdictional claims in published maps and institutional affiliations.

Ready to submit your research? Choose BMC and benefit from:

- fast, convenient online submission

- thorough peer review by experienced researchers in your field

- rapid publication on acceptance

- support for research data, including large and complex data types

- gold Open Access which fosters wider collaboration and increased citations

- maximum visibility for your research: over $100 \mathrm{M}$ website views per year

At $\mathrm{BMC}$, research is always in progress.

Learn more biomedcentral.com/submission 